Review

\title{
Sustainability in Building and Construction within the Framework of Circular Cities and European New Green Deal. The Contribution of Concrete Recycling
}

\author{
Alessandra Bonoli ${ }^{1,2, *}$, Sara Zanni ${ }^{3}\left[\right.$ and Francisco Serrano-Bernardo ${ }^{2} \mathbb{D}$ \\ 1 Department of Civil, Chemical, Environmental and Materials Engineering, University of Bologna, \\ via Terracini 28, 40131 Bologna, Italy \\ 2 Department of Civil Engineering, University of Granada, E.T.S. de Ingeniería de Caminos, Canales y Puertos, \\ Campus Universitario de Fuentenueva, Edificio Politécnico, 18071 Granada, Spain; fserber@ugr.es \\ 3 Department of Management, University of Bologna, Via Capo di Lucca 34, 40126, Bologna, Italy; \\ sara.zanni7@unibo.it \\ * Correspondence: alessandra.bonoli@unibo.it
}

Citation: Bonoli, A.; Zanni, S.;

Serrano-Bernardo, F. Sustainability in Building and Construction within the Framework of Circular Cities and European New Green Deal. The Contribution of Concrete Recycling. Sustainability 2021, 13, 2139.

https://doi.org/10.3390/su13042139

Academic Editor: Sandra Pereira

Received: 31 December 2020

Accepted: 8 February 2021

Published: 17 February 2021

Publisher's Note: MDPI stays neutral with regard to jurisdictional claims in published maps and institutional affiliations.

Copyright: (c) 2021 by the authors. Licensee MDPI, Basel, Switzerland. This article is an open access article distributed under the terms and conditions of the Creative Commons Attribution (CC BY) license (https:// creativecommons.org/licenses/by/ $4.0 /)$.

\begin{abstract}
Climate change and ecological crisis are a huge threat to Europe and the world. To overcome these challenges, Europe adopted the New Green Deal as a strategy transforming the Union into a competitive resource-efficient economy without greenhouse gas emissions and become carbon neutral in a few decades. The European Green Deal includes the new circular economy action plan, highlighting the importance of a products' "green design", saving raw materials, and waste prevention oriented along the entire life cycle of products. Construction and buildings represent one of the key topics for the green transition. In the European Union, buildings are responsible for $40 \%$ of our energy consumption and $36 \%$ of greenhouse gas emissions, which are mainly caused by construction, usage, renovation, and demolition. Improving environmental efficiency can play a key role in reaching the carbon neutrality of Europe that is expected to be achieved by 2050. In this research, it was explored how Eco-design, as an innovative approach in buildings and construction, Life Cycle Thinking and Life Cycle Assessment, as fundamental supporting tools in sustainability, and finally appropriate and effective Construction and Demolition Waste recycling processes, particularly oriented to concrete recycling according to the case studies analyzed, can promote a circular economy in buildings and construction.
\end{abstract}

Keywords: eco-design sustainability; LCA; circular economy; Circular Cities; EU Green Deal; CDW; buildings and construction

\section{Introduction}

The built environment is commonly recognized as a major contributor to global environmental impacts. Up to $40 \%$ of all raw materials extracted from the lithosphere are consumed by this sector, responsible for roughly $50 \%$ of global greenhouse emissions [1]. In the European Union, buildings and construction are responsible for a large part of the total energy consumption (about 40\%) and of greenhouse emissions (36\%) [2], along the entire chain from construction to demolition, passing through utilization and maintenance.

More efficient use of materials, both at the beginning and at the end of their life, would make a major contribution to reducing the environmental impacts of construction. This benefit would be achieved principally by a depletion reduction of finite natural resources and a reduced dependence on landfills.

The construction industry is also one of the world's largest consumers of natural resources, with an annual usage of 50 billion tons of sand and gravel. As the main component of concrete, they are essential for all kinds of construction work, and considering the growing world population and urbanization, their demand will further increase in 
the following years. The global natural inert materials' usage already has a considerable impact on the environment and human lives. Most of the used sand is mined from fluvial or coastal areas with several severe environmental impacts risk in terms of various rivers or beaches and islands ecosystems preservation, and hydrological balance [3].

The need for more sustainable and improved use of natural resources in this sector has been recognized at the EU level by the Raw Material Initiative [4]. This is reflected in the challenging target that has been set to increase the recovery and recycling of Construction and Demolition Waste (CDW) across Europe.

Approximately 1 billion tonnes of waste, which is around one-third of the total amount generated in EU 27 each year, comes from Construction and Demolition (C and D) activities [5]. However, at present, large quantities of these materials eventually end up in landfills, without any form of recovery or reuse. CDW have to be urgently managed in an appropriate and efficient way. Because of the impacts, not only on environmental but also from economic and social points of view, Buildings and Construction (B and C) represent a hot spot related to all the other sectors [6].

According to the UNEP-UN Environment Programme definition [7], the Green Economy takes into due account all the natural resources from which the human species benefits without any compensation paid. This is a holistic approach, not only an economic one, involving all community activities, particularly addressed in two crucial areas: procurement and sustainable use of natural capital and resources. In this context, a fundamental role is played by government policies on sustainability, first of all, by a decline at a worldwide level put forward by the UN Agenda 2030 in 2015 [8], and four years later, by the EU New Green Deal [9]. This represents an intensive and effective roadmap for making sustainable the EU economy by transforming ecological and climate issues and environmental challenges into opportunities. The European Green Deal refers to construction as one of the key topics for the green transition, contributing in a fundamental way to the carbon neutrality of Europe that has to be achieved by 2050 [10]. As pillar of that process, the new Circular Economy Action Plan was adopted in March 2020, highlighting the importance of a products' "green design" that has to be oriented to a reduction of raw materials consumption and waste prevention along the entire life cycle of products [11]. The main goal was identified in a robust reduction of CDW pursued by waste prevention and improvement in recycling processes allowing a high quality and high efficiency secondary raw materials production. The EU Commission will act in several directions, considering many production fields, with particular attention given to B and C. The European strategy for a Sustainably Built Environment [12] represents in fact a whole and exhaustive plan aiming to guarantee a coherent integration between all the policy strategic areas such as climate change, energy and resource efficiency, CDW management, etc. This strategy will promote circularity principles of construction throughout the lifecycle of buildings starting from an update to the Construction Product Regulation. The strategy includes the possibility to require appropriate recycled content for construction products, at the same conditions of quality and safety, and to adopt a Life Cycle Assessment (LCA) methodology in public procurement. Furthermore, according to Circular Economy (CE) principles, new goals in CDW recovery targets, in part, an energy efficiency implementation that is expected by a lifecycle performance optimization and a longer lifespan of construction heritage.

New EU policies are promoting energy performances in buildings by considering financial leverages, making easier financing access for building assets renovation. In that direction, also the "Clean energy for all Europeans package" [13] promoted a robust revision of the previous energy in buildings directives with the aim to drive the EU clean energy transition. Each country will integrate its national energy and climate plans (NECPs) by adopting an energy strategy in buildings for the period of 2021-2030, including nearly zeroenergy buildings, energy performance certificates, and smart technology in new buildings actions, with the aim to reach the $32.5 \%$ EU target in energy efficiency by 2030 [14].

The European Green Deal has been recently supported by the new EU Action Plan "Towards a Zero Pollution Ambition for air, water, and soil—building a Healthier Planet 
for Healthier People" [15], having the purpose of acting on particular climate change and pollution issues promoting prevention, remediation, and monitoring activities.

Finally, the Circular Cities and Regions Initiative (CCRI) [16] represents an innovative focal point of the Circular Economy Action Plan, highlighting the importance of pursuing advanced solutions and actions at the local and regional level. B and C could represent an excellent field of interest for Circular Cities strategies for minimizing environmental and social impacts in compliance with the sustainability principles. They can put into practice more appropriate behavior in consumption and resources supply as well as in waste prevention, recovery, and recycling, contributing to achieving UN Agenda 2030 SDGs 11 ("Make cities and human settlements inclusive, safe, resilient and sustainable") and 12 ("Ensure sustainable consumption and production patterns").

CDW management has outlined over time the strategies through which waste must be treated; these methods are positioned within a hierarchical scale, in relation to the preference given to them from an environmental point of view, that is, from the impact they can determine on the environment. The environmental impact resulting from the use of these strategies is in increasing order, from lowest to highest. The principles underlying the hierarchy are the minimization of resource consumption and the prevention of environmental impact, which represent the two pillars of sustainability in construction [17]. The three strategies, 'Reduce, Reuse, Recycle', are well known in the field of waste management as the 3Rs of the hierarchy of CDW management methods [18], and CE in B and C. The waste reduction strategy offers two major benefits: minimizing the generation of CDW waste and reducing the costs for the transport of waste. The reduction method is considered the most efficient and effective for optimizing CDW management and eliminating many environmental and disposal problems. It must be seriously estimated in the case of refusal from $C$ and D activities it is inevitable and that the 'zero waste' condition is not achievable. It could be, nevertheless, approached by improving the efficiency dematerialization of the processes. Reuse generally means the use of the same component in the construction process more than once. It can be done both considering an 'old life' reuse, with the possibility of using a material or a component for the same previous function (i.e., the wooden formwork), and a 'new life' reuse for a new function (such as the use of concrete fractions or tiles for basic materials for the streets). Reuse requires minimal treatment of the material and in addition to low energy consumption. Recycling is recognized today as the most practicable and preferable CDW management strategy compared to all the others, as well as desirable from an environmental point of view. The goal is to reprocess the waste to obtain secondary raw materials to be used mostly as aggregate for the production of mortar and concrete. This not only fulfills the goal of recycling but also results in economic benefits. The production of secondary raw materials implies a series of well recognized advantages, such as the reduction of demand for new resources and of transport and energy costs, the exploitation of waste that otherwise would be landfilled, and the preservation of land areas and of the general conditions of the environment. Reused and recycled raw materials also represent an added value in terms of sustainability in construction. Appropriate material selection, in fact, plays a crucial role in reducing the embodied energy and other environmental impacts of a building, and it can constitute additional value in also labeling and environmental certification achievement. For instance, the green building rating system LEED (Leadership in Energy and Environmental Design) [19], the building classification method based on energy consumption and ecological footprint evaluation, includes a complete category (Materials and Resource) that aims at selecting materials that are assumed to be "green" including material with recycled content and reused materials. In the effort to quantify the whole impacts of materials arising during each step in the whole supply chain (i.e., manufacturing, transportation, construction, and operation), including end of life management and valorization, several national and international regulation and labeling systems are considering a life cycle thinking approach. It allows a holistic evaluation of all environmental, social and economic impacts deriving from $\mathrm{B}$ and $\mathrm{C}$ activities. For instance, in Italy, the so called "CAM" (Minimal Environmental 
Criteria) plan, related to buildings, introduced by the Environmental Ministry in 2017 [20], and in Spain, the buildings certification system ("Código Técnico de la Edificación" [21], support the Public Sector Contracts and Procurement regulations. Both these two policies assume environmental life cycle assessment (ELCA) and life cycle costs assessment (LCC) as sustainability evaluation and validation methods. Also, the already mentioned LEED, in its last updated edition [22], introduced the use of whole building life cycle assessment (WBLCA) as a compliance option for earning credits. In particular, it was introduced a new credit named "building lifecycle impact reduction", supporting Eco-design by using life cycle assessments in an effort to allow objective comparison of quantified environmental performance for various materials [23].

In order to understand in which way Life Cycle Thinking and Eco-design approaches can be successfully addressed in B and C, a preliminary explorative literature review has been performed.

\section{Materials and Methods}

The literature review was accomplished by an initial search of more than 250 papers. The research string used included the following terms: Sustainability, Construction, LCA, Life Cycle Thinking, Eco-design, Circular Economy, and CDW (Construction and Demolition Waste).

The initial set of results included 130 papers. Screening was performed based on more effective keywords each other related, resulting in 73 papers. The final selection was carried out by reading all the abstracts and excluding 57 papers not fitting with the main topics.

Therefore, the final set of articles included 73 papers, 57 published in peer-reviewed Journals, six book chapters, and 10 conference papers.

The literature available testifies and interest toward these topics increasing sensibly over the last twenty years, with more than 53\% of the papers published since 2017 (Figure 1).

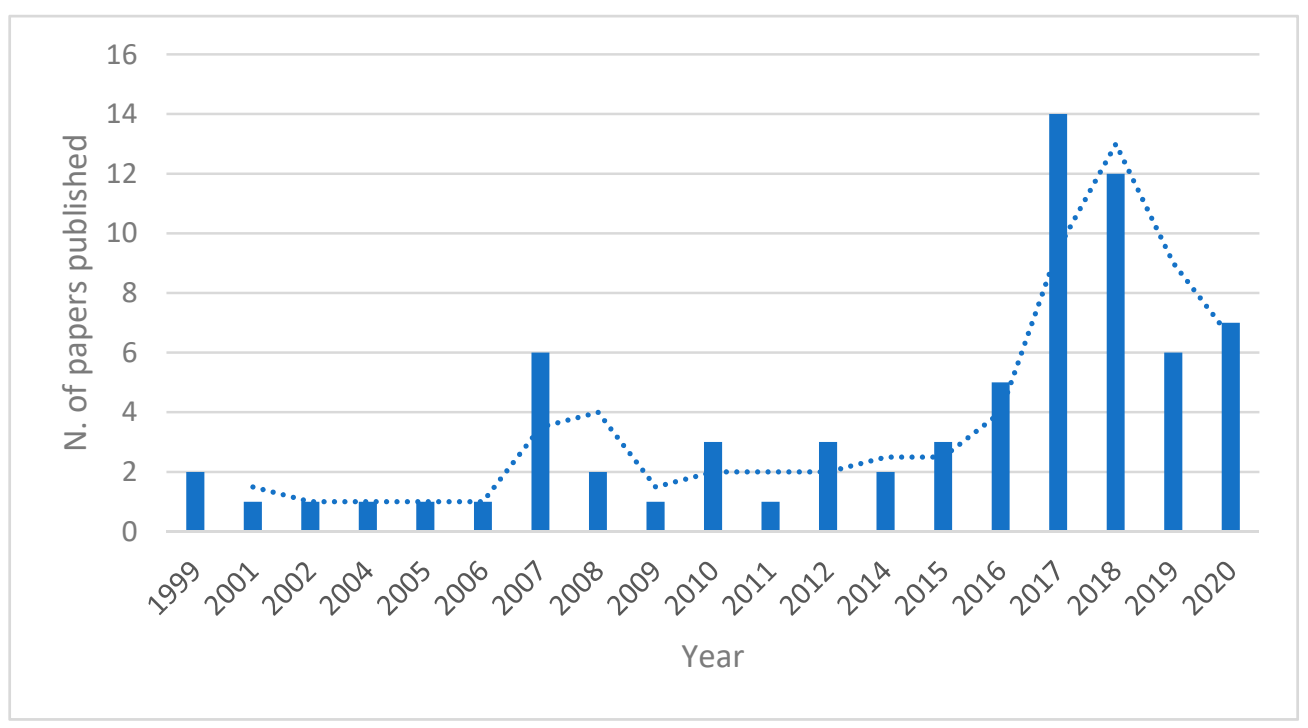

Figure 1. Number of paper published over the years.

These articles were, then, clustered based on the topic into nine classes, describing the macro-themes, i.e., Sustainable Development, Circular Economy, Eco-efficiency of product and processes, Performance and material Recycling, or more methodological ones, as techniques for impact assessment, i.e., Carbon Footprint, Life cycle Assessment (LCA), Life Cycle Sustainable Assessment (LCSA), or for sustainable product development, i.e., Eco-Design (Figure 2). 


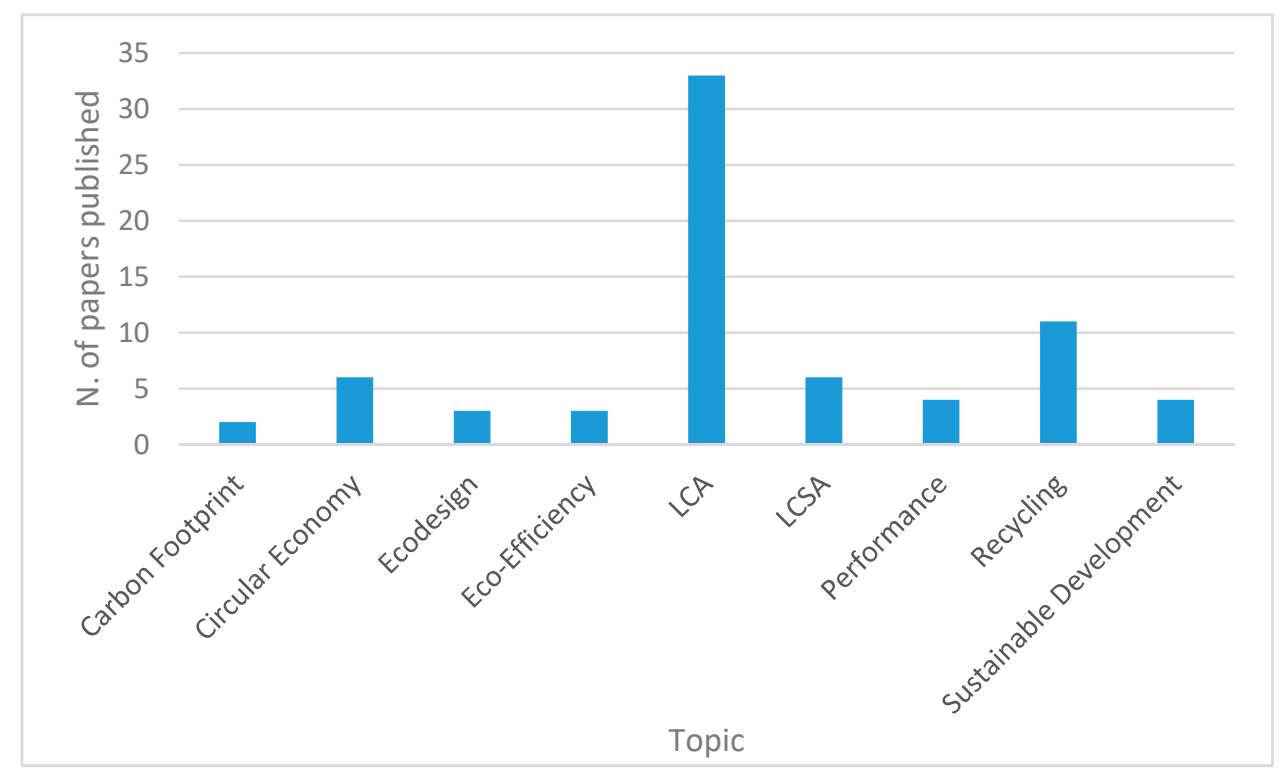

Figure 2. Number of papers published per specific topic. LCA: life cycle assessment; LCSA: life cycle sustainable assessment.

The papers were published in international peer-reviewed Journals constitute quite a recognizable stream of research, hosted on Journals engaged on topics related either to material recycling, such as Resources Conservation and Recycling and Waste Management, or assessment methods, like International Journal of Life Cycle Assessment, or clean production in general, as Journal of Cleaner Production (Figure 3).

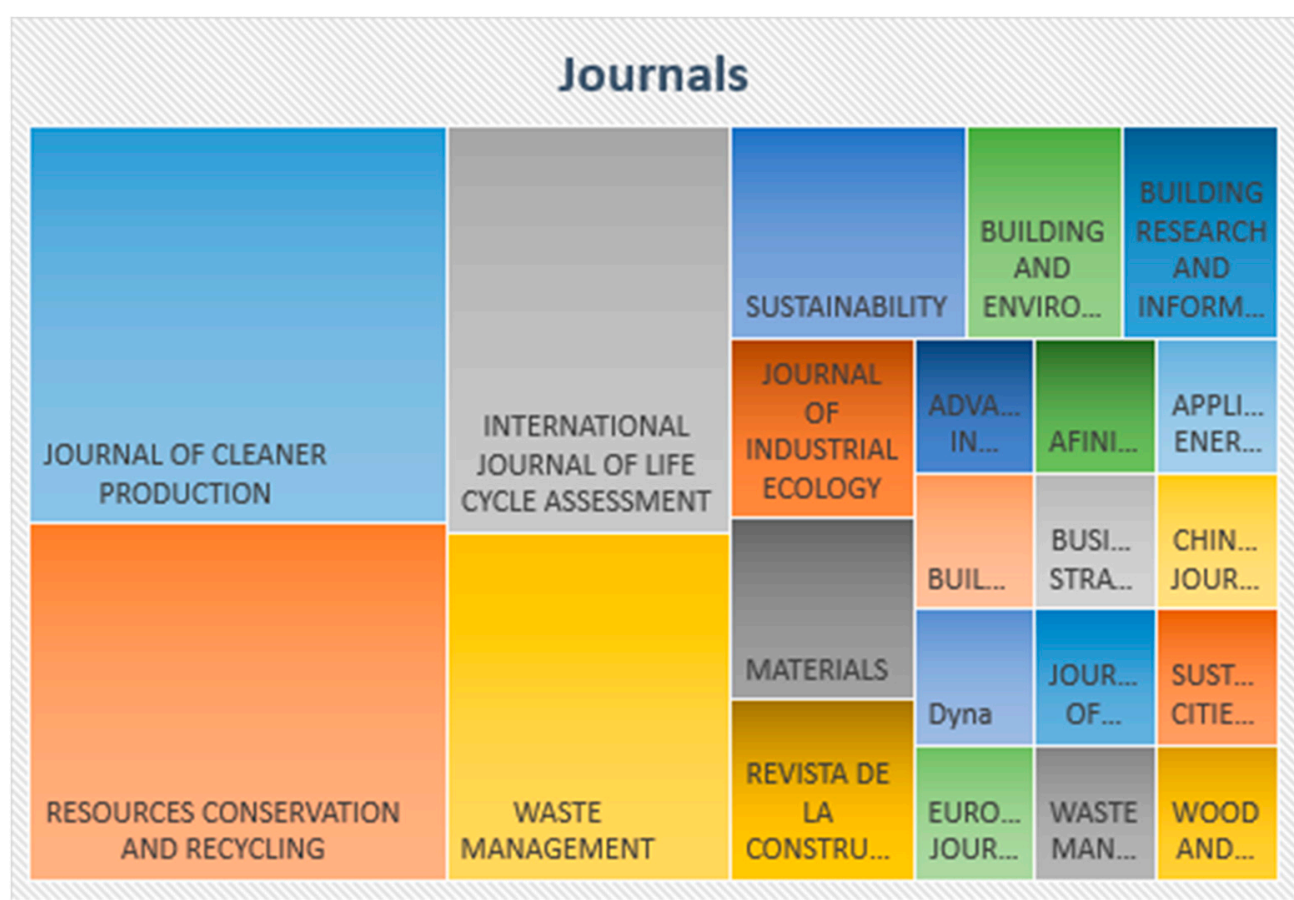

Figure 3. International peer-reviewed journals hosting papers on the topics analyzed.

\section{Results and Discussion}

The literature review performed highlighted the presence of two pillars underpinning the academic conversation (Figure 4). One is more oriented to the systemic view required for policy formulation, referring to the topics of sustainable development in general, circular economic systems, and recycling as a fundamental approach to waste management. The 
other tends to ground the researches into a more product-oriented approach, rooted in performance and efficiency evaluations and the application of an advanced tool for the impact assessment of products and processes, as well as the development of Eco-design methodologies and products. This last topic, in particular, configures as the natural bridge between the two frameworks, as it takes advantage of product-oriented tools to develop solutions integrated with more systemic views. In the following, the two frameworks are presented and supported by the analysis of case studies of particular significance.

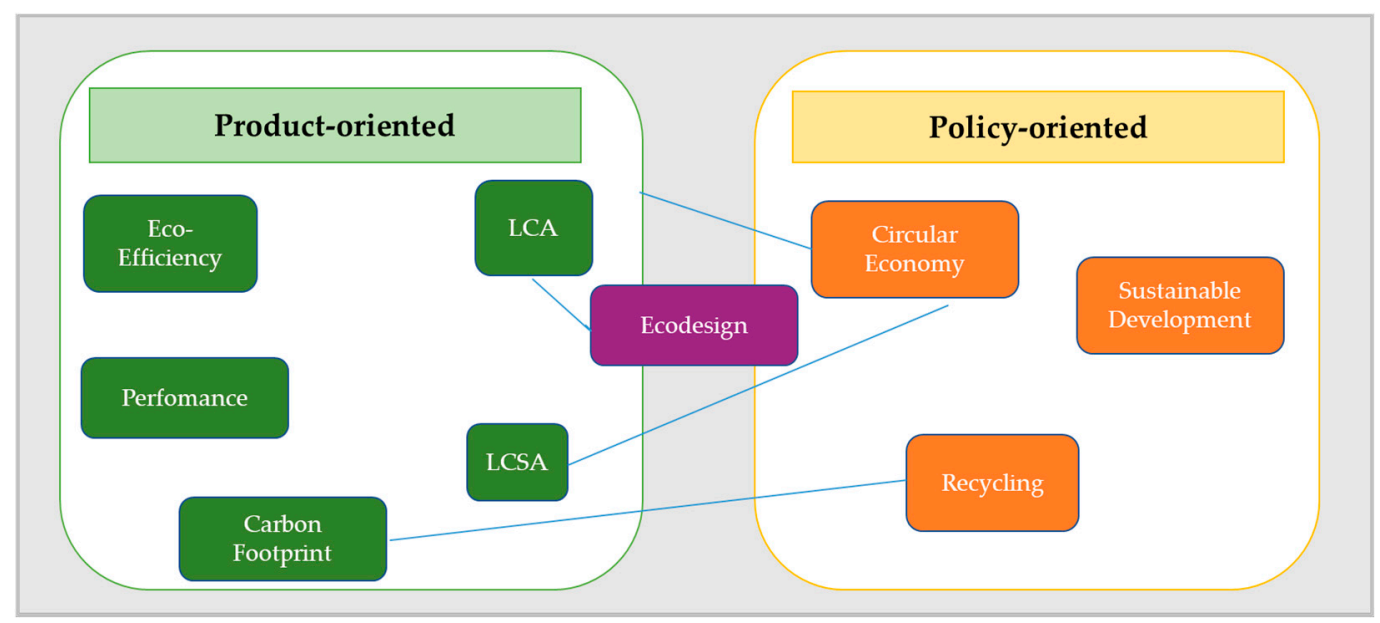

Figure 4. Summary of the frameworks identified within the review.

\subsection{Product-Oriented Framework}

A remarkable stream of research deals with product-oriented approaches, typically promoting the efficiency and performance of products in terms of environmental impacts, and the tools were supporting both assessment and product development, such as Life Cycle Assessment, Sustainability Assessment, and Carbon Footprint.

\subsubsection{Life Cycle Thinking, Life Cycle Assessment and Environmental Product Declaration}

Over their lifetime, products (goods and services) can contribute to various environmental impacts. Life Cycle Thinking considers the range of impacts throughout the life of a product.

The fundamental aim of Life Cycle Thinking is to reduce overall environmental impacts. This can involve trade-offs between impacts at different stages of the life cycle. However, care needs to be taken to avoid shifting problems from one stage to another. Reducing the environmental impact of a product at the production stage may lead to a greater environmental impact further down the line. An apparent benefit of a waste management option can therefore be canceled out if not thoroughly evaluated.

The European Commission has developed guidelines for LCAs that are fully compatible with international standards. These aim to ensure quality and consistency based on scientific evidence when carrying out assessments. The LCA quantifies environmental impacts by assessing emissions, consumed resources, and pressures on health and the environment.

The assessment of the life cycle of a product or of a process represents a standardized EN ISO methodology [24] that allows to carry out a complete study on the environmental impacts by considering the entire life cycle ('from the cradle to the grave', in the traditional concept of linear products, or "from the cradle to the cradle" in the CE perspective). It includes the extraction and processing of raw materials, the manufacturing phase of the products, transport, and distribution, the use and possible reuse of the product or its parts, collection, storage, recovery, and the end of life management.

LCA represents an excellent tool in the case of several alternatives or solutions comparison [25], being able as well to validate decisions. LCA is able to analyze, quantify 
and evaluate the causes of the environmental impact determined by a product during its life cycle, and can usefully demonstrate the products and processes sustainability from a quantitative point of view by estimating and weighting each environmental impact categories, such as Climate Change or minerals consumption.

LCA and Environmental Product Declarations (EPD) represent important sources of information in applications in B and C also in the context of Design for Environment [26].

EPDs aim to certify the environmental performance of construction products and services on the basis of consistent, accurate, and certain data and evaluations. In that way, LCA can represent the starting point for a reliable EPD, becoming the most interesting assessment tool of the environmental performance of buildings [27].

As for a product or service, LCA can be applied to buildings, taking into consideration all the phases ranging from the birth of a work to the end of its useful life, in order to calculate the relative costs and environmental impact of these activities.

In particular, it includes the phases of planning, design, construction, management of the asset and its maintenance, redevelopment, or disposal and all these phases have a robust impact on the environment.

The importance of analysis and evaluation that are as accurate as possible in terms of the environmental impact of the building life cycle has to be considered in order to understand the sustainability of the process, optimizing the available resources utilization and end of life management.

Sustainability in buildings and construction, assessed by a whole Life Cycle Assessment, begins with the extraction of natural resources and the production of energy and components; substances and energy belong to the production, transport, and use phases as well as the recovery, reuse, or disposal phase. Using the life cycle approach means balancing and defining positive environmental, economic and social impacts by defining environmental risks and opportunities, thus recognizing the damage or potential environmental risks that occur at each stage [28].

In the same way, it is possible to prevent constructive or inappropriate design choices [29] that mitigate a certain environmental impact from causing other environmental damage, producing a shift in problems from one phase of the life cycle to another or from a type of impact to another.

To date, this methodology has found numerous applications in construction. It has been used as a basic method for establishing standards for awarding eco-labels to building materials or "green buildings" certification and for supporting the definition of methods for the assessment of the ecological compatibility of construction products [30], for developing building materials life cycle database [31].

Numerous tools exist for the assessment of the environmental compatibility of buildings, based on a life cycle approach [32]. The first kind of method works by aggregating the results of LCA studies developed on building materials and components, including the evaluation of the energies, on the basis of a quantitative assessment of the environmental impact by the contributions of the different components of the building materials [33]. Other methods assess qualitatively environmental performances of buildings on the basis of checklists [34] or key performance indicators [35].

\subsubsection{Eco-Design in Constructions}

The design process is a very important phase for the sustainability of a building by improving environmental, social, and economic sustainability, minimizing environmental impacts by making decisions based on a holistic perspective, mainly if based on a Life Cycle Thinking approach.

According to the Eco-design Working Plan 2016-2019 [36], it is necessary to assume effective quantitative and qualitative criteria to assess material efficiency, to use upcycled materials, and an integrated design. By using this approach, the European Commission is working on the Eco-design toolbox that looks at all the products and materials from the qualitative and quantitative point of view by integrating technical and technological 
aspects with environmental impacts, such as energy consumption and greenhouse gases emissions. The integration of environmental criteria into design thinking is a new and challenging area, and product Eco-design activities can actually encourage step changes in Small and Medium Enterprises (SMEs) in the construction and building sector [37].

According to the common definitions, Eco-design, ecological design, or sustainable design is the incorporation of environmental aspects into the design and into product development [38] in order to avoid negative environmental impacts throughout its useful life. Appropriate tools are necessary to perform at best an Eco-design process, also by considering a strict connection with technical and economic issues and business strategy [39].

Eco-design can offer different benefits and opportunities also to B and C companies, not only environmentally but also from the economic and social point of views. The environmental performance can be improved by optimizing inputs and outputs of the construction process, reducing resource consumption (energy, raw materials, and water), emissions and waste, and increasing the efficiency of the system [39]. An effective Ecodesign implementation firstly needs the appropriate tools but also an inclusion inside business models and operation. Many SMEs in the B and C sectors still face difficulties in the effective implementation of these methods because of barriers and challenges associated with Eco-design methods and to their implementation. Several barriers include specific knowledge about tools, awareness of the environmental issues, time-consuming efforts, limited financial and personnel resources [40].

Within the Eco-design approach, the Integrated Product Policy can represent a relevant guiding tool for the $B$ and $C$ sector towards best practices in design, suggesting instruments and solutions useful for the greening of products during their whole life cycle [41].

As the Eco-design is rooted in a more comprehensive view of the product as a system, integrated into a broader value-network, it represents the ideal bridge toward the policyoriented framework.

\subsection{Policy-Oriented Framework}

A wider perspective characterizes the policy-oriented framework identified within the body of literature included in the review. This more systemic approach toward the study of sustainable management of CDW encompasses elaborations about their role within the Circular Economy, the recycling options technologically available, and its contribution to the design of new materials, twinning, in this sense, the focus on Eco-design presented above.

\section{Circular Economy, CDW Recycling, and New Materials Design}

Circular Economy is proposed as an economic system planned to reuse materials in subsequent production cycles, extending their useful life, with the aim of reducing and, if possible, eliminating any waste. According to a circularity approach, materials, resources, goods, and products have to be maintained in the economic system for as long as possible, and the production of waste is minimized, with consequent important environmental and economic advantages [42].

Western societies have increasingly encouraged the use of natural resources for the production of a considerable amount of goods and products, often with a limited lifetime duration. This means a resource is consumed faster than the natural systems regeneration capability, and, at the same time, production of waste higher than the absorption and transformation capacity of the environment. These phenomena have also affected the construction industry. Today we can say that this approach is no longer sustainable. Indeed, the demand for aggregates has generated high impacts on the territory and the significant amount of CDW that have to be properly managed, avoiding landfilling or, as a worst-case scenario, illegal dumping.

The $\mathrm{C}$ and $\mathrm{D}$ industry is responsible for about $50 \%$ of the non-renewable raw materials consumption and $40 \%$ of the total amount of solid waste production [18]. CDW has to be considered as a severe priority in waste management and recycling by European Union. 
Thanks to an effective CE perspective that has to be entirely reached and applied, CDW recycling and reuse have to be implemented because also the high value and quality, and the good performance of the related secondary raw materials also by incorporating the CDW into fresh-made concrete and other construction elements.

$\mathrm{CDW}$ is one of the heaviest and most voluminous waste streams generated worldwide. Huge amounts of wastes, with the higher percentage still landfilled, are produced in quarries and processing plants (700 million tons every year in Europe), as well as in construction and demolition stages (870 million tons per year in Europe representing $40 \%$ of special wastes) (Figure 5) [43]. CDW consists of different materials, including concrete, bricks, gypsum, wood, glass, metals, plastic, asbestos, many of which can be recycled and can substitute natural aggregates for new constructions. The idea to improve and enlarge recycled materials coming from CDW is related to the CE perspective applied to the $\mathrm{B}$ and $\mathrm{C}$ field.

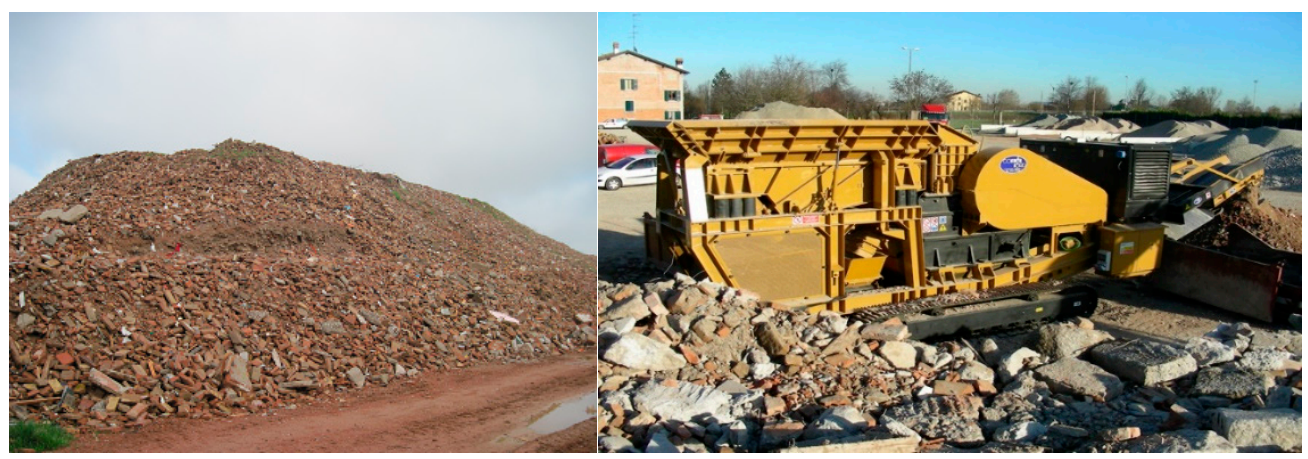

Figure 5. Examples of construction and demolition waste (CDW) management. On the left, unsorted cumulus of materials from emergency management in the event of the Emilia earthquake (2012; on the right, a mobile CDW treatment plant.

Some examples demonstrate the possibility of recovery and reuse of materials derived from the demolition of existing structures. For instance, the materials for the new Juventus Stadium construction in Turin have been recovered from the demolition of the old "Delle Alpi" Stadium, by using $40,000 \mathrm{~m}^{3}$ of concrete, reused for the structural embankment of the new plant, and $5000 \mathrm{t}$ of recycled steel, $2000 \mathrm{~m}^{2}$ of recycled glass and $300 \mathrm{t}$ of recycled aluminum. It means notable environmental and economic advantages: a reduction in waste production and in new raw materials supply, and in addition remarkable economic savings that were estimated at around 2 million euros [44].

According to several studies, it can be seen that recycled aggregates can be used for different construction purposes. CDW aggregates can be used for producing low environmental impact masonry mortars [45] or low-cost bricks [46], satisfying the international standards and providing better performances such as thermal conductivity than normal earth bricks [47]. CDW aggregates are excellent for asphalt mixture, meeting the standards of mix design criteria for heavy traffic (Figure 6). Furthermore, with a usage of a mixture with an appropriate percentage in recycled aggregates, a reduction of the thickness of the asphalt layer can be obtained, resulting in both a reduction of environmental impact and of the total costs of the road construction [48].

An interesting study shows the possibility to consider an appropriate mixture, combining fine recycled aggregates (30\%) and coarse natural aggregates for paving [49]. A similar analysis [50] demonstrates the feasibility of incorporating a fine fraction of aggregates from CDW in the manufacture of cement-based masonry mortars based on recycled concrete, mixed and ceramic aggregates. 


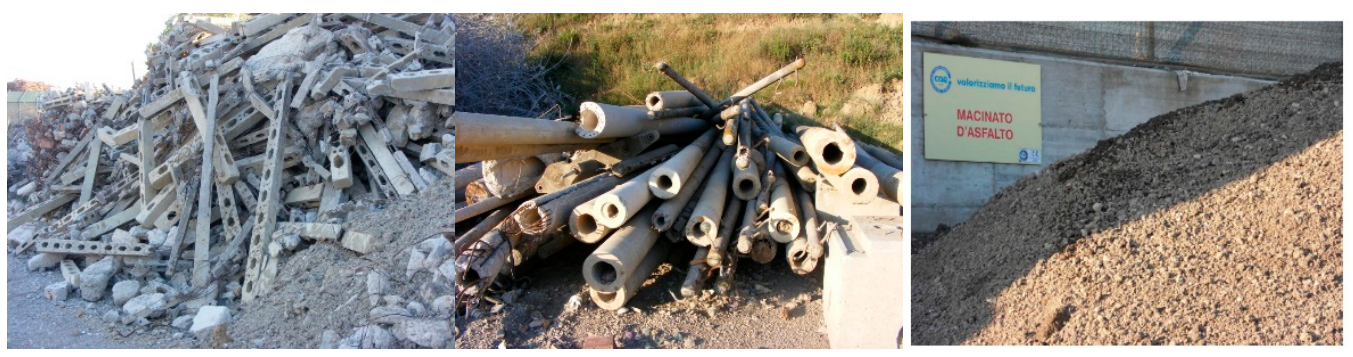

Figure 6. Examples of properly managed CDW materials, deriving from selective demolitions (from the left: concrete structural elements, mixed materials from water systems, and finally, ready-to-use ground asphalt from road pavement demolition).

The use of recycled CDW aggregates is worldwide recognized as appropriate to create asphalt mixes for the construction of urban asphalt roads and paving of urban roads [51-54].

With respect to the utilization of CDW in concrete, it is possible to recognize that the use of the fine part of crushed concrete into new mixtures of concrete present similar compressive strength to a reference concrete when the mixtures are composed of up to $30 \%$ of CDW aggregates [55]. CDW can be used for the production of building materials, replacing the natural aggregate for the production of bricks. The high performance and properties low-cost bricks can be produced by using CDW as aggregate and lime or cement as additives, as shown in a case study in Brazil [56].

Geopolymers containing concrete aggregates and fired clay from CDW showed promising properties for use in building elements even with the $50 \%$ of aggregates and more [57].

Some authors [58-61] conducted studies on recycled aggregates for the production of new concrete by analyzing and comparing standards and guidelines of various countries around the world. That approach is almost interesting in order to determine the quality criteria for the physical and mechanical properties of concrete, highlighting the feasibility and appropriateness of using recycled aggregates and in an environmental assessment perspective.

Several studies have executed on CDW management, recovery, and recycling, paying particular attention to the production of recycled aggregates, their properties, and possible utilization in a wide range of building applications by using a CE perspective [62].

Several kinds of industrial scraps and by-products are actually used as aggregate in construction to produce new concrete, at different content value, in relation to the expected properties, such as waste foundry sand [63] or fly ashes [64]. Recycled aggregates are also applied in new digital construction like 3D printing with excellent performances also in terms of reduced environmental impact and costs [65]. Besides inert material, also other $\mathrm{CDW}$, such as plastics and glass, which are actually very often landfilled, can be recycled for different applications to produce aggregate and concrete [66]. With a global production of more than 5.3 billion cubic meters per year, there may be a huge potential for using recycled plastics in concrete [67]. Consequently, the significant use of waste plastics as aggregate in construction can contribute to a rise in the recycled plastic waste rate. The utilization of this type of waste in concrete can have a positive effect on the properties of the material and definitively beneficial from an environmental point of view.

It is clear that more research is required on influencing factors such as the treated plastic aggregates, shape and size aggregates, favorable mix compositions of concrete, curing conditions to grow confidence in the use of plastic aggregates in concrete.

In the same way, a life cycle analysis can quantify the environmental impacts assessing how the demolition and subsequent recycling and reuse operations can bring clear environmental benefits. Considering the potential environmental impacts related to the end of life of residential buildings, it is possible to highlight how the choice of an adequate selective demolition technique can increase the quantity and quality of recyclable materials with excellent effects in terms of environmental sustainability. An interesting study 
performed in a building demolition case [68] shown environmental advantages related to selective demolition by applying an attributional life cycle assessment able to highlight and quantify the contributions of each end-of-life phase (i.e., separation and collection of main components, sorting, and recycling of the waste, etc.). Steel components recycling results of the primary importance, accounting for $65 \%$ of the total avoided impacts related to respiratory inorganics, $89 \%$ of those for global warming, and $73 \%$ of those for natural resources depletion.

Several studies identify environmental performances by using LCA and specific properties and appropriate behavior in some local contexts around the world, demonstrating the favorable impact derived from CDW recycling.

The life cycle assessment methodology can be applied to compare the environmental performance, in a specific context, such as in a northern Italy region, of the CDW management by identifying critical aspects and possible improvement actions [69]. LCA and LCC can also be really useful to evaluate the economic and environmental implications of both conventional demolition and selective demolition. Some scenarios are considered, in a specific case study in Portugal, based on possible different waste management options, encouraging selective demolition over conventional type by demonstrating advantages both by economic and environmental impact assessment [70]. Another example is provided by a case study developed in the area of Bologna, Italy [71], in which the evaluation of different management options for CDW was coupled with the design of concrete mixes, implementing CDW-derived aggregates as a partial replacement for natural aggregates, traditionally cultivated in the area. LCA methodology guided the assessment of the environmental impact of the options designed in comparison with commercial concrete mixes. The model allowed to identify the breakeven point for the compensation of the trade-off between the impact generated by CDW processing and the benefit obtained by the replacement. However, findings suggest that aggregates replacement should be coupled by a parallel replacement in the cement component in order to trigger a substantial decrease of the environmental impact of the newly designed mixes.

A particular recycling process, oriented in wood polymer composite (WPC) production, was able to achieve a robust amount in CDW recovery and recycling in Finland [72]. The environmental impact of WPC production, by using specific fractions of CDW (i.e., wood, plastic, plasterboard, and mineral wool), wa demonstrated to be reduced in comparison with the baseline situation of a common CDW treatment and recycling.

Technological, economic, and environmental aspects are relevant to orient operational CDW management, usefully assessed by life cycle assessment and life cycle cost with the aim to support sustainable policymaking.

A rigorous study [73] presents integrated LCA and LCC analysis in four alternative scenarios (i.e, landfilling, downcycling, advanced recycling, and recycling after selective demolition) for CDW end-of-life in the Belgian region of Flanders. Recycling and selective demolition present environmental impact reductions of $36 \%$ and $59 \%$, respectively, compared to landfilling. Avoided landfilling and substitution of natural resources is the main environmental benefit of CDW recycling, while, in the case of selective demolition, the most significant advantage comes from the recovery of metals and wood during dismantling. Economically, landfilling is the worse alternative with a total cost of $79 \mathrm{M} € / \mathrm{y}$, followed by selective demolition (47.8 M€), recycling (27.9 M€), and downcycling (27.8 M€).

In the same way, an evaluation of appropriate CDW management can be considered by comparing the two common end of life possibilities, recycling or disposal, by quantifying both the eco-efficiency [74] or the ecological footprint [75] or the economic impact and the total indirect costs. CDW landfilling represents an economic and environmental impact, producing an effect on human health-related and consisting of ineffective mitigation costs, while recycling means a saving of total external cost [76].

Finally, the implementation of best practices for CDW management across the entire construction value chain could drastically improve resource efficiency and reduce environmental impact by reducing waste generation, minimizing transport impacts, maximizing 
reuse and recycling by improving the quality of secondary materials, and optimizing the environmental performance of treatment methods [77].

\section{Conclusions}

According to the literature, the attention to $B$ and $C$ sustainability is definitively growing. This sector represents one of the most natural resources (raw materials and energy) demanding and contributes to a huge amount of greenhouse gas emissions and solid waste production. For these reasons, the European Commission has been developing a long-term strategy to tackle the issues. All last policies and action plans, such as the New Green Deal, the Circular Economy Action Plan, and the Circular Cities and Regions Initiative, just to mention the most important, are rowing in the same direction. A coherent and integrated is required to achieve ambitious goals in a few decades, by 2050: European carbon neutrality, zero pollution, low resource consumption, zero energy buildings, whole and perfect circularity, zero-waste, and orientation to prevention.

All European countries also have to implement these processes at a national level by active and effective actions to promote sustainability in B and C.

Nowadays, a more effective CE approach is mandatory, allowing waste to be reprocessed or remanufactured, prolonging the life cycle of the material, and therefore, alleviating the rising amount of CDW disposed of. Recycling and closing the material loop are efficient strategies for reducing the environmental impacts of the building industry. Further research has to be encouraged to promote innovative methods for high-value advanced recycle, to obtain high quality secondary raw materials. To boost the opportunities in this sense, it is crucial to demonstrate both environmental and economic advantages derived from appropriate life cycle thinking and Eco-design approaches. In fact, an effective recycling process starts from the design phase of the material, when the real impact of sustainability-oriented solutions can be triggered, and the quality and quantity of recycled materials depends on proper end of life planning and management. LCA can demonstrate environmental advantages and compare different solutions in terms of materials, components, or processes, while, for example, Life Cycle Costing (LCC) can act on the economic aspects. The Environmental Product Declaration, based on an LCA and applied in B and C, could represent an effective and standardized way of quantifying and communicate the environmental impacts in future buildings. For these reasons, the enhancement of assessment tools, in terms of both reliability and widespread application is strategic, especially when applied with a systemic view.

Green Public Procurement or the Integrated Product Policy can represent effective tools Eco-design oriented supporting B and C sector, designers and policymakers towards sustainability path. Several authors highlight al-so the importance of standardization of the processes and of the methodologies to develop a design or an environmental assessment, to apply universally recognized measure units, and to account for impacts. Also, in that issue, European action plans and guidelines can provide an effective contribution.

According to several pieces of research, it can be demonstrated that recycled CDW has good physical and technical properties, effective performance and can be appropriately used as a substitution of natural aggregates and inert materials. In the same way, the importance of utilizing recycled CDW, both in terms of environmental sustainability and economic advantages, has been proved. Quality control and certification are essential to prompt and sustain stakeholder's confidence in the recycled material. When properly processed and categorized, in fact, it may be considered as excellent secondary raw material, fitting for several uses in construction activities, and this has to be supported by greater governmental intervention in the form of legislations and standardizations.

There is still strong resistance by some practitioners to the use of secondary raw materials despite numerous studies, such as those analyzed in this paper; however, if mainly oriented in concrete recycling and consolidated worldwide practices, research has demonstrated the high quality of some recycled materials and their suitability for different applications. 
However, the existing Eco-design research can provide a greater understanding of the barriers and opportunities facing designers and companies wishing to develop environmentally responsible products. Many companies face difficulties in the effective implementation of these methods because of obstacles and challenges which are associated with Eco-design tools and methods. Practitioners and companies have to be supported by simplifications and, at the same, by an effective recognition of the sustainability approach's complexity and importance.

Finally, construction materials eco-labels and green buildings certification can contribute to support and promote B and C sustainability.

Author Contributions: Conceptualization, A.B.; methodology, S.Z. and A.B.; validation, F.S.-B. and A.B.; formal analysis, A.B.; investigation, A.B. and S.Z.; data curation, A.B. and S.Z.; writing original draft preparation, A.B.; writing-review and editing, A.B., S.Z., and F.S.-B.; visualization, A.B., S.Z., and F.S.-B.; supervision, F.S.-B. All authors have read and agreed to the published version of the manuscript.

Funding: This research received no external funding.

Institutional Review Board Statement: Not applicable

Informed Consent Statement: Not applicable

Data Availability Statement: Data available from authors, upon request

Conflicts of Interest: The authors declare no conflict of interest.

\section{References}

1. Ruuska, A.; Häkkinen, T. Material efficiency of building construction. Buildings 2014, 4, 266-294. [CrossRef]

2. Marie Rousselot, E. Energy Efficiency Trends in Buildings in Europe I Policy Brief I ODYSSEE-MURE. Available online: https: //www.odyssee-mure.eu/publications / policy-brief/buildings-energy-efficiency-trends.html (accessed on 28 December 2020).

3. Beiser, V. The World in a Grain: The Story of Sand and How It Transformed Civilization by Vince Beiser. Available online: https:/ / www.goodreads.com/book/show/36950075-the-world-in-a-grain (accessed on 28 December 2020).

4. Policy and Strategy for Raw Materials I Internal Market, Industry, Entrepreneurship and SMEs. Available online: https:/ /ec. europa.eu/growth/sectors/raw-materials / policy-strategy_en (accessed on 28 December 2020).

5. Home-Eurostat. Available online: https:/ / ec.europa.eu/eurostat/ (accessed on 28 December 2020).

6. Hendriks, C.F.; Janssen, G.M.T. Use of recycled materials in constructions. Mater. Struct. 2003, 36, 604-608. [CrossRef]

7. Towards a Green Economy: Pathways to Sustainable Development and Poverty Eradication. Sustainable Development Knowledge Platform. Available online: https: / / sustainabledevelopment.un.org /index.php?page=view\&type=400\&nr=126\&menu=35 (accessed on 28 December 2020).

8. The Sustainable Development Agenda-United Nations Sustainable Development. Available online: https://www.un.org/ sustainabledevelopment/development-agenda/ (accessed on 28 December 2020).

9. A European Green Deal I European Commission. Available online: https:/ / ec.europa.eu/info/strategy/priorities-2019-2024/ european-green-deal_en (accessed on 28 December 2020).

10. European Green Deal: Construction Products Europe AISBL. Available online: https://www.construction-products.eu/newsevents / latest-news / european-green-deal (accessed on 28 December 2020).

11. New Circular Economy Action Plan. Available online: https://ec.europa.eu/commission/presscorner/detail/en/ip_20_420 (accessed on 28 December 2020).

12. Level(s). Available online: https://ec.europa.eu/environment/topics/circular-economy/levels_en (accessed on 28 December 2020).

13. Clean Energy for all Europeans Package I Energy. Available online: https:/ / ec.europa.eu/energy/topics/energy-strategy/cleanenergy-all-europeans_en (accessed on 28 December 2020).

14. In Focus: Energy Efficiency in Buildings I European Commission. Available online: https://ec.europa.eu/info/news/focusenergy-efficiency-buildings-2020-feb-17_en (accessed on 28 December 2020).

15. Commission Outlines Road to Zero Pollution Action Plan. Available online: https://ec.europa.eu/environment/news/ commission-outlines-road-zero-pollution-action-plan-2020-10-01_en (accessed on 28 December 2020).

16. Circular Cities and Regions Initiative / European Commission. Available online: https:/ / ec.europa.eu/info/research-and-innovation/ research-area/environment/circular-economy/circular-cities-and-regions-initiative_en (accessed on 28 December 2020).

17. Sustainability in Building Design and Construction-Designing Buildings Wiki. Available online: https://www.designingbuildings . co.uk/wiki/Sustainability_in_building_design_and_construction (accessed on 28 December 2020).

18. Ginga, C.P.; Ongpeng, J.M.C.; Daly, M.K.M. Circular Economy on Construction and Demolition Waste: A Literature Review on Material Recovery and Production. Materials 2020, 13, 2970. [CrossRef] 
19. LEED Rating System I U.S. Green Building Council. Available online: https:/ / www.usgbc.org/leed (accessed on 28 December 2020).

20. I Criteri Ambientali Minimi I Ministero Dell'Ambiente e della Tutela del Territorio e del Mare. Available online: https://www. minambiente.it/pagina/i-criteri-ambientali-minimi (accessed on 28 December 2020).

21. Instituto de Ciencias de la Construcción Eduardo Torroja, C. CSIC para la Dirección General de Arquitectura, Vivienda y Suelo del Ministerio de Fomento Codigo Tecnico de la Edificaciòn. Available online: https: / www.codigotecnico.org/ (accessed on 28 December 2020).

22. LEED v4 / U.S. Green Building Council. Available online: https:/ / www.usgbc.org/leed/v4 (accessed on 28 December 2020).

23. Meneghelli, A. Whole-building embodied carbon of a North American LEED-certified library: Sensitivity analysis of the environmental impact of buildings materials. Build. Environ. 2018, 134, 230-241. [CrossRef]

24. ISO-ISO 14040:2006-Environmental Management-Life Cycle Assessment_Principles and Framework. Available online: https:/ / www.iso.org/standard/37456.html (accessed on 29 December 2020).

25. Monteiro, H.; Freire, F. Life-cycle assessment of a house with alternative exterior walls: Comparison of three impact assessment methods. Energy Build. 2011, 47, 572-583. [CrossRef]

26. Galindro, B.M.; Welling, S.; Bey, N.; Olsen, S.I.; Soares, S.R.; Ryding, S. Making use of life cycle assessment and environmental product declarations: A survey with practitioners. J. Ind. Ecol. 2020, 24, 965-975. [CrossRef]

27. Passer, A.; Lasvaux, S.; Allacker, K.; De Lathauwer, D.; Spirinckx, C.; Wittstock, B.; Kellenberger, D.; Gschösser, F.; Wall, J.; Wallbaum, H. Environmental product declarations entering the building sector: Critical reflections based on 5 to 10 years experience in different European countries. Int. J. Life Cycle Assess. 2015, 20, 1199-1212. [CrossRef]

28. Göswein, V.; Rodrigues, C.; Silvestre, J.D.; Freire, F.; Habert, G.; König, J. Using anticipatory life cycle assessment to enable future sustainable construction. J. Ind. Ecol. 2020, 24, 178-192. [CrossRef]

29. Peterson, B. How Much of an Impact Do Green Building Designs Really Have on the Environment? I Energy Central. Available online: https:/ / energycentral.com/c/ec/how-much-impact-do-green-building-designs-really-have-environment (accessed on 29 December 2020).

30. Bruce-Hyrkäs, T.; Pasanen, P.; Castro, R. Overview of Whole Building Life-Cycle Assessment for Green Building Certification and Ecodesign through Industry Surveys and Interviews. In Proceedings of the Procedia CIRP; Elsevier B.V.: 2017; Part of special issue 25th CIRP Life Cycle Engineering (LCE) Conference, Copenhagen, Denmark, 30 April-2 May 2018; Volume 69, pp. 178-183.

31. Martínez-Rocamora, A.; Solís-Guzmán, J.; Marrero, M. LCA databases focused on construction materials: A review. Renezw. Sustain. Energy Rev. 2016, 58, 565-573. [CrossRef]

32. Bach, R.; Hildebrand, L. A Comparative Overview of Tools for Environmental Assessment of Materials; RWTH Aachen University: Aachen, Germany, 2018.

33. Harris, D.J. A quantitative approach to the assessment of the environmental impact of building materials. Build. Environ. 1999, 34, 751-758. [CrossRef]

34. Shen, L.-Y.; Hao, J.L.; Tam, V.W.-Y.; Yao, H. A Checklist for assessing sustainability performance of construction projects. J. Civ. Eng. Manag. 2007, 13, 273-281. [CrossRef]

35. Mellado, F.; Lou, E.C.W.; Becerra, C.L.C. Synthesising performance in the construction industry: An analysis of performance indicators to promote project improvement. Eng. Constr. Archit. Manag. 2019, 27, 579-608. [CrossRef]

36. EUROPEAN COMMISSION Ecodesign Working Plan 2016-2019-EU Agenda. Available online: https://euagenda.eu/ publications / european-commission-ecodesign-working-plan-2016-2019 (accessed on 29 December 2020).

37. Denac, M.; Obrecht, M.; Radonjič, G. Current and potential ecodesign integration in small and medium enterprises: Construction and related industries. Bus. Strateg. Environ. 2018, 27, 825-837. [CrossRef]

38. Eco-Design-European Environment Agency. Available online: https://www.eea.europa.eu/help/glossary/eea-glossary/ecodesign (accessed on 29 December 2020).

39. Vicente, J.; Frazao, R.; De Silva, F.M. Ecodesign Tools: One basis to operationalize Sustainable Design. In Proceedings of the VI CIPED-International Congress on Design Research, Lisbon, Portugal, 10-12 October 2011.

40. Ahn, Y.H.; Pearce, A.R.; Wang, Y.; Wang, G. Drivers and barriers of sustainable design and construction: The perception of green building experience. Int. J. Sustain. Build. Technol. Urban Dev. 2013, 4, 35-45. [CrossRef]

41. Toolbox-IPP_Environment-European Commission. Available online: https://ec.europa.eu/environment/ipp/toolbox.htm (accessed on 29 December 2020).

42. Ghisellini, P.; Ripa, M.; Ulgiati, S. Exploring environmental and economic costs and benefits of a circular economy approach to the construction and demolition sector. A literature review. J. Clean. Prod. 2018, 178, 618-643. [CrossRef]

43. Luciano, A.; Reale, P.; Cutaia, L.; Carletti, R.; Pentassuglia, R.; Elmo, G.; Mancini, G. Resources Optimization and Sustainable Waste Management in Construction Chain in Italy: Toward a Resource Efficiency Plan. Waste Biomass Valorization 2020, 11, 5405-5417. [CrossRef]

44. Sertaç Erten, S.Ö. [PDF] OF MEGA-EVENT STADIUMS (1990-2012) I Semantic Scholar. Available online: https://www. semanticscholar.org/paper/OF-MEGA-EVENT-STADIUMS-(-1990-2012-)-Erten-Özfiliz/03d24c6bad0d67b693afff6e45e37f399 $95 \mathrm{fca} 10$ (accessed on 28 December 2020).

45. Cuenca-Moyano, G.M.; Martín-Morales, M.; Bonoli, A.; Valverde-Palacios, I. Environmental assessment of masonry mortars made with natural and recycled aggregates. Int. J. Life Cycle Assess. 2019, 24. [CrossRef] 
46. Dos Reis Oliveira, P.C.; van der Geest, H.G.; Kraak, M.H.S.; Westveer, J.J.; Verdonschot, R.C.M.; Verdonschot, P.F.M. Over forty years of lowland stream restoration: Lessons learned? J. Environ. Manag. 2020, 264, 110417. [CrossRef]

47. Dos Reis, G.S.; Cazacliu, B.G.; Cothenet, A.; Poullain, P.; Wilhelm, M.; Sampaio, C.H.; Lima, E.C.; Ambros, W.; Torrenti, J.M. Fabrication, microstructure, and properties of fired clay bricks using construction and demolition waste sludge as the main additive. J. Clean. Prod. 2020, 258, 120733. [CrossRef]

48. Fatemi, S.; Imaninasab, R. Performance evaluation of recycled asphalt mixtures by construction and demolition waste materials. Constr. Build. Mater. 2016, 120, 450-456. [CrossRef]

49. Pederneiras, C.M.; Durante, M.D.P.; Amorim, Ê.F.; Ferreira, R.L.d.S. Incorporation of recycled aggregates from construction and demolition waste in paver blocks. Rev. IBRACON Estruturas Mater. 2020, 13. [CrossRef]

50. Saiz Martínez, P.; González Cortina, M.; Fernández Martínez, F.; Rodríguez Sánchez, A. Comparative study of three types of fine recycled aggregates from construction and demolition waste (CDW), and their use in masonry mortar fabrication. J. Clean. Prod. 2016, 118, 162-169. [CrossRef]

51. Ossa, A.; García, J.L.; Botero, E. Use of recycled construction and demolition waste (CDW) aggregates: A sustainable alternative for the pavement construction industry. J. Clean. Prod. 2016, 135, 379-386. [CrossRef]

52. Remišová, E.; Decký, M.; Mikolaš, M.; Hájek, M.; Kovalčík, L.; Mečár, M. Design of Road Pavement Using Recycled Aggregate. In Proceedings of the IOP Conference Series: Earth and Environmental Science, Beijing, China, 7-8 July 2016; IOP Publishing: Bristol, UK, 2016; 44, p. 022016.

53. Herrador, R.; Pérez, P.; Garach, L.; Ordóñez, J. Use of Recycled Construction and Demolition Waste Aggregate for Road Course Surfacing. J. Transp. Eng. 2012, 138, 182-190. [CrossRef]

54. Teijón-López-Zuazo, E.; Vega-Zamanillo, Á.; Calzada-Pérez, M.Á.; Robles-Miguel, Á. Use of Recycled Aggregates Made from Construction and Demolition Waste in Sustainable Road Base Layers. Sustainability 2020, 12, 6663. [CrossRef]

55. Evangelista, L.; de Brito, J. (PDF) Environmental Life Cycle Assessment of Concrete Made with Fine Recycled Concrete Aggregates. Available online: https://www.researchgate.net/publication/235939400_Environmental_life_cycle_assessment_of_concrete_ made_with_fine_recycled_concrete_aggregates (accessed on 28 December 2020).

56. Contreras, M.; Teixeira, S.R.; Lucas, M.C.; Lima, L.C.N.; Cardoso, D.S.L.; da Silva, G.A.C.; Gregório, G.C.; de Souza, A.E.; dos Santos, A. Recycling of construction and demolition waste for producing new construction material (Brazil case-study). Constr. Build. Mater. 2016, 123, 594-600. [CrossRef]

57. Panizza, M.; Natali, M.; Garbin, E.; Tamburini, S.; Secco, M. Assessment of geopolymers with Construction and Demolition Waste (CDW) aggregates as a building material. Constr. Build. Mater. 2018, 181, 119-133. [CrossRef]

58. Martín-Morales, M.; Zamorano, M.; Valverde-Palacios, I.; Cuenca-Moyano, G.M.; Sánchez-Roldán, Z. Quality control of recycled aggregates (RAs) from construction and demolition waste (CDW). In Handbook of Recycled Concrete and Demolition Waste; Elsevier Inc.: Amsterdam, The Netherlands, 2013; pp. 270-303. ISBN 9780857096906.

59. Silva, R.V.; de Brito, J.; Dhir, R.K. Use of recycled aggregates arising from construction and demolition waste in new construction applications. J. Clean. Prod. 2019, 236, 117629. [CrossRef]

60. Oikonomou, N.D. Recycled concrete aggregates. Cem. Concr. Compos. 2005, 27, 315-318. [CrossRef]

61. Anike, E.E.; Saidani, M.; Ganjian, E.; Tyrer, M.; Olubanwo, A.O. The potency of recycled aggregate in new concrete: A review. Constr. Innov. 2019, 19, 594-613. [CrossRef]

62. Hossain, M.U.; Ng, S.T. Critical consideration of buildings' environmental impact assessment towards adoption of circular economy: An analytical review. J. Clean. Prod. 2018, 205, 763-780. [CrossRef]

63. Doğan-Sağlamtimur, N. Waste Foundry Sand Usage for Building Material Production: A First Geopolymer Record in Material Reuse. Adv. Civ. Eng. 2018, 2018. [CrossRef]

64. Hansen, T.C. Recycled concrete aggregate and fly ash produce concrete without portland cement. Cem. Concr. Res. 1990, 20, 355-356. [CrossRef]

65. Han, Y.; Yang, Z.; Ding, T.; Xiao, J. Environmental and economic assessment on 3D printed buildings with recycled concrete. J. Clean. Prod. 2021, 278, 123884. [CrossRef]

66. Mohammadinia, A.; Wong, Y.C.; Arulrajah, A.; Horpibulsuk, S. Strength evaluation of utilizing recycled plastic waste and recycled crushed glass in concrete footpaths. Constr. Build. Mater. 2019, 197, 489-496. [CrossRef]

67. Babafemi, A.J.; Šavija, B.; Paul, S.C.; Anggraini, V. Engineering properties of concrete with waste recycled plastic: A review. Sustainability 2018, 10, 3875. [CrossRef]

68. Vitale, P.; Arena, N.; Di Gregorio, F.; Arena, U. Life cycle assessment of the end-of-life phase of a residential building. Waste Manag. 2017, 60, 311-321. [CrossRef] [PubMed]

69. Borghi, G.; Pantini, S.; Rigamonti, L. Life cycle assessment of non-hazardous Construction and Demolition Waste (CDW) management in Lombardy Region (Italy). J. Clean. Prod. 2018, 184, 815-825. [CrossRef]

70. Coelho, A.; De Brito, J. Generation of construction and demolition waste in Portugal. Waste Manag. Res. 2011, 29, 739-750. [CrossRef] [PubMed]

71. Zanni, S.; Simion, I.M.; Gavrilescu, M.; Bonoli, A. Life Cycle Assessment Applied to Circular Designed Construction Materials. Procedia CIRP 2018, 69, 154-159. [CrossRef] 
72. Liikanen, M.; Grönman, K.; Deviatkin, I.; Havukainen, J.; Hyvärinen, M.; Kärki, T.; Varis, J.; Soukka, R.; Horttanainen, M. Construction and demolition waste as a raw material for wood polymer composites - Assessment of environmental impacts. J. Clean. Prod. 2019, 225, 716-727. [CrossRef]

73. Di Maria, A.; Eyckmans, J.; Van Acker, K. Downcycling versus recycling of construction and demolition waste: Combining LCA and LCC to support sustainable policy making. Waste Manag. 2018, 75, 3-21. [CrossRef] [PubMed]

74. Simion, I.M.; Zanni, S.; Bamonti, S.; Bonoli, A.; Gavrilescu, M.; Bignozzi, M.C. Eco-efficient management of construction and demolition waste. Procedia Environ. Sci. Eng. Manag. 2014, 1. [CrossRef]

75. Simion, I.M.; Ghinea, C.; Maxineasa, S.G.; Taranu, N.; Bonoli, A.; Gavrilescu, M. Ecological footprint applied in the assessment of construction and demolition waste integrated management. Environ. Eng. Manag. J. 2013, 12. [CrossRef]

76. Marzouk, M.; Azab, S. Environmental and economic impact assessment of construction and demolition waste disposal using system dynamics. Resour. Conserv. Recycl. 2014, 82, 41-49. [CrossRef]

77. Gálvez-Martos, J.L.; Styles, D.; Schoenberger, H.; Zeschmar-Lahl, B. Construction and demolition waste best management practice in Europe. Resour. Conserv. Recycl. 2018, 136, 166-178. [CrossRef] 